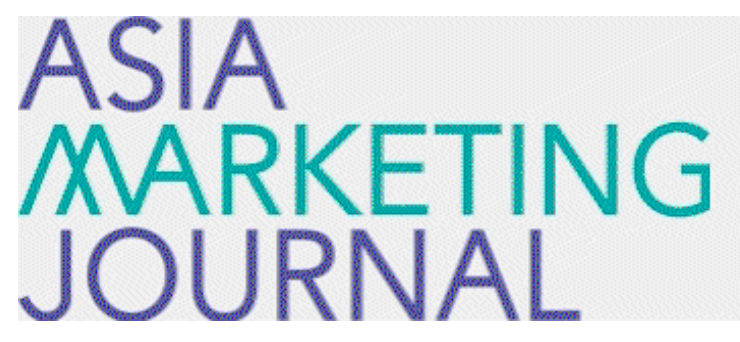

ASIA MARKETING JOURNAL

Volume 10 | Issue 2

Article 6

7-30-2008

\title{
소비자의 역할변화에 대한 탐색적 연구
}

Chang Jo Yoo

Follow this and additional works at: https://amj.kma.re.kr/journal

Part of the Marketing Commons

\section{Recommended Citation}

Yoo, Chang Jo (2008) "소비자의 역 할변화에 대한 탐색적 연 구," Asia Marketing Journal: Vol. 10 : Iss. 2 , Article 6.

Available at: https://doi.org/10.53728/2765-6500.1217

This Article is brought to you for free and open access by Asia Marketing Journal. It has been accepted for inclusion in Asia Marketing Journal by an authorized editor of Asia Marketing Journal. 


\section{소비자의 역할변화에 대한 탐색적 연구: \\ 새로운 소비문화 발현자로서의 소비자}

\section{Exploratory Study on Consumers' Role Change: Consumers as Originators of New Consumption Culture}

유 창 조(Yoo, Changjo)*

본 글은 한국마케팅저널 편집규정 2조 4항에 근거한 것이다. 2조 4항: 열린 마당(open plaza)은 book review, issue, short essay 등을 다루며 A4 4-5장 정도의 분량으로 편집위원장이 원로회원 및 특정회원에게 원고를 청탁할 수 있다.

지금까지 소비자의 행동을 분석하는 대표적인 접근방식으로 소비자 정보처리 관점(consumer information processing perspective)과 경험적 관점(experiential perspective)이 제시되어 왔다. 1960년대 후반에 들어서면서 채택되기 시작한 정보처리 관점은 소비자를 이성적인 의사결정 자로 가정하고 이들의 제품선택결과와 및 정보 처리결과를 예측하기 위한 다양한 연구들이 진 행되어 왔다(Betmann 1979). 1980년 이후 소 비자행동 연구자들은 소비자의 이성적이니 못 한 의사결정에 대해서 관심을 기울이기 시작하 였고, 소비자의 재미, 즐거움, 환상과 같은 경험 적인 측면을 분석하기 시작했고(Hirshman and Holbrook 1982; Holbrook and Hirshman 1983), 그에 따라 경험마케팅, 감성마케팅 등과 같은
용어들이 마케팅 분야에 등장하기 시작했다 (Schmitt 2003).

그러나 이러한 두가지 대표적인 접근방식들은 기본적으로 소비자를 수동적인 구매자(주어진 제품 대안 중에서 선택할 수밖에 없다는 측면 에서의 수동성을 의미함)를 가정하고 있다. 즉, 소비자들은 기업이 제공하는 상표대안들 중에 서 어떤 과정을 거쳐 상표를 선택할 것인가의 관점에서 탐구되어 왔다. 그러나 최근 소비현상 에서 소비자의 주도적인 역할이 자주 언급되고 있다(Seybold 2002; Sharma and Sheth 2004; 임종원과 양석준 2006). 소비자가 생산에 참여 하는 현상(예: prosumer), 소비자가 스스로 판 매역할을 수행하는 현상(예: salesumer)이 그 예들이다(주우진과 김재범 2002). 이러한 소비

* 동국대학교 경영학과 교수(yoo@dongguk.edu) 
자의 새로운 역할은 뉴 미디어와 혁신 기술의 발달로 소비자가 생산 및 판매에 참여할 수 있 는 기회가 확대되면서 나타나는 현상으로 볼 수 있다(Kelly 1998; Jenkins 2006). 한편, 최 근 소비자들은 더 나아가서 새로운 소비가치 및 소비문화를 스스로 만들어내기도 한다(예: 2002년 및 2006년의 길거리 응원, 2008년의 촛 불시위 등). 이러한 현상들은 기업과 고객과의 관계를 근본적으로 재조명할 필요성을 제기해 준다. 본 논문에서는 이러한 새로운 현상을 가 능하게 한 융합의 개념을 살펴보고, 새로운 소 비자 역할의 변화과정을 탐색하고자 한다.

\section{I. 기술 및 미디어의 융합 (convergence)}

1990년대 정보통신 기술의 발달과 웹의 상업 적 적용이 빠르게 적용되고 있고, 이러한 새로 운 기술들은 커뮤니케이션 개념을 변화시키고 있다. 즉, 과거 기업에서 소비자로의 일방적인 커뮤니케이션이 기업과 소비자 간의 쌍방향 커 뮤니케이션으로 바뀌고 있다. 또한 뉴 미디어 들은 소비자와의 개별적 접촉을 가능하게 해 주면서 진정한 의미의 일대일 마케팅 개념이 구현되고 있다. 즉, 기업은 개별 소비자의 욕구 와 가치를 정확하게 인식하고 이에 맞추어 개 별적으로 판매하는 방식(mass customization) 을 지향하면서 범위(예: 다양한 옵션과 선택폭 의 제공)와 속도(예: 정보와 제품의 적시 제 공)의 경쟁을 시작하고 있다(유창조 2008). 또 한 이러한 기술의 발달은 디지털 융합(digital convergence)으로 발전되고 있고, 그에 따른 기 업 활동 및 산업분야간 재편이 자주 논의되고 있다. 디지털 혁명은 미디어 산업을 재편하고 있고, 그에 따라 전통적인 산업구분의 경계가 희석되면서 산업 내 경쟁에서 산업간 경쟁구도 로 바뀌고 있다. 이러한 변화는 유무선 방송, 통신 영역을 포괄하는 복합 디지털 미디어 그 룹의 출현을 가시화시키고 있고, 그 결과 미디 어 산업구조가 기존의 수평적 산업구조(방송, 미디어, 통신, 인터넷 등의 각각의 산업구조) 에서 복합적 산업구조로 재편되고 있다(유창 조 2008).

\section{II. 소비자의 역할 변화}

이러한 새로운 기술과 융합의 개념은 기업과 소비자와의 관계를 근본적으로 변화시키기고 있다. 새로운 기술이 제공되면서 소비자는 과거 와 달리, 많은 정보를 획득하고 재생산할 능력 을 갖게 되었고, 소비자간 정보교환이 용이하게 되면서 소비자들 간 확대된 네트워크를 형성할 수 있게 된 것이다. 그에 따라 소비자들은 기업 과의 관계에서 과거와는 달리 보다 능동적인 자세를 취할 수 있게 되었다. 예를 들어, 집단 으로 제품의 문제점을 지적하기도 하고 불매 운동을 펼치는 모습이 쉽게 목격된다.

본 연구는 이와 같은 환경의 변화가 기업과 소비자간 관계에서 소비자 역할의 변화를 탐색 해 보고자 한다. 미래 소비자 역할의 변화를 예 측하는 것은 매우 어려운 과제이지만, Turner (1969)가 제시하는 무경계성의 개념(liminality 
또는 margin)은 이를 예측하는 단서를 제공해 준다. Arnold van Gennep(1909)은 의례적 전 통이 변화되는 과정을 분리(segregation), 무경 계(margin), 집합(aggregation)으로 제안한 바 있다. 여기서 무경계의 개념은 기조의 질서에서 새로운 질서로 정립되는 과정이라고 보면 된다. 즉, 뉴 미디어와 혁신기술의 등장함에 따라 과 거의 질서(산업간 분리, 일방향적 커뮤니케이션 등)가 무너지면서 무경계성이라는 현상이 나타 나고, 그에 따라 기존의 질서가 다시 재편된다 고 볼 수 있다. 이러한 단계적 변화는 최근 소 비자의 역할 변화를 비교적 정확하게 설명할 수 있는데, 이를 단계별로 정리하면 다음과 같다.

\section{1 수동적 구매자로서의 소비자 (기존의 질서)}

과거의 기업과 소비자 간의 관계는 기업에서 소비자로의 일방적 관계로 볼 수 있다, 즉, 기 업이 생산한 제품을 소비자에게 제공하고 제품 에 대한 대부분의 정보가 기업의 주도하에 일 방적으로 제공되었다고 볼 수 있다. 소비자는 매우 제한적인 정보의 범위 내에서 주어진 대 안들 중 선택할 수밖에 없는 상황이었고, 소비 자는 선택시 자신의 희생을 최소화(customer sacrifice: 소비자는 자신이 진정으로 원하는 것 과 실제로 구매하는 것과의 차이)하기 위한 의 사결정을 할 수밖에 없었다(Pine and Gilmore 1999). 즉 이 시기 소비자가 수행할 수 있는 역할 은 수동적인 구매자로 국한된다고 볼 수 있다.

\section{2 협업자(collaborator)로서의 소비자 (liminality: communita의 형성)}

새로운 기술로 무장된 뉴미디어는 소비자에게 무한한 정보를 제공해 주고 있고, 소비자는 이 를 효율적으로 탐색할 수 있게 되었다. 또한 소 비자들은 아무런 제약없이 커뮤니티를 구성하 여 구성원들 사이의 자유로운 정보교환을 하기 시작했다. 과거의 소비자들이 매우 제한된 네트 워크를 갖고 있었다면, 뉴 미디어 시대의 소비 자는 확대된 커뮤니티를 갖게 되었다고 볼 수 있는데, McAlexander et al.(2002)은 기업과 고객간의 새로운 관계에서 소비자의 주도성을 반영하는 고객 중심의 브랜드 커뮤니티 모형 (customer-entric brand community)을 제안한 바 있다. 이와 같이 고객의 주도성이 높아지면 서 Pine \& Gilmore(1999)는 고객과의 상호작 용을 통하여 고객을 관여(engagement)시키는 것을 기업의 핵심적인 성공요인이라고 언급한 바 있다(Pine and Gilmore 1999).

이와 같이 향상된 상호작용성은 과거의 일방 적 커뮤니케이션 개념을 쌍방향의 개념으로 바 꾸고 있고, 그에 따라 소비자의 참여적 소비 현상이 늘어나면서 소비자는 이제 기업의 활동 에 참여하는 협업자로 그 역할을 바꾸고 있다 (Jenkins 2006). 예를 들어 이미 소비자의 생산 자적 역할(prosumer: 제품을 소비하면서 제품을 만드는 역할을 겸함) 과 판매자 역할(salesumer: 제품을 소비하면서 판매원의 역할을 수행)은 이미 자주 언급된 바 있다. Sharma \& Sheth (2004)는 이를 바탕으로 기업과 소비자간 리버 스 마케팅이라는 개념을 제안한 바 있는데, 이 는 고객이 이제는 역으로 기업에게 어떤 마케 
팅을 제안하는 현상을 예측한 것이다.

한편, 소비자들은 기업과 관계없이 자신들을 위한 브랜드 커뮤니티를 형성하면서 소비자들 간 확대된 네트워크(예: 할리 데이비슨의 HOG)를 갖추고 기업과의 관계에서 능동적인 영향력을 행 사하고 있다(Schouten and McAlexander 1995). 이와 같이 소비자가 확대된 네트워크를 갖추고 제품과 관련된 충분한 정보를 확보할 수 있게 되면서 기업과 소비자와의 관계는 일방적인 관 계에서 쌍방향적인 관계로 발전하게 되었다. 이 와 같이 기존의 일방적인 질서가 무너지면서 기업과 고객의 관계는 무경계성을 갖게 된다. 즉 기업과 고객은 서로 분리된 객체가 아니라 하나의 공동체(Tuner가 제시하는 communita의 개념임)로 인식하는 것이다. 최근 공연무대에서 공연자가 관람객의 참여를 기획하는 모습이 자 주 목격되고 있고, 예술품 관련 전시회에서도 작가와 관람객이 서로 섞여 진행되는 행사는 이제 필수적인 프로그램으로 정착되고 있다 ((Lancaster 1997; 유창조, 백지은 2006). 또한, 홍대 앞 예술시장의 모든 구성원들은 판매자, 구매자, 고객의 역할을 함께 수행하는 모습을 보여주기도 한다(유창조, 김미나 2007). 이와 같이 기업과 고객의 역할이 분리되지 않고 협 업자의 관점에서 새로운 공동체의 개념이 생겨 나고 있고, 그에 따라 기업과 고객은 새로운 질 서를 모색하고 있다고 하겠다.

\section{3 새로운 소비문화 발현자로서의 소비자 (지위의 역전)}

이러한 소비자와 기업과의 무경계성을 거치면 서 소비자들은 기업과 쌍방향적인 관계에서 더
나아가 독립된 개체로서 정체성을 확립하기 시 작했다. 최근 소비자들은 기업이 제공하는 제품 을 단순히 사용하지 않고, 자신의 욕구를 완성 하기 위해 개조하기도 하고, 다양한 치장을 통 하여 개성을 표현하기도 하고, 주어진 정보를 이용하고 새로운 창작물을 만들기도 하며, 기업 이 미처 생각하지 못한 새로운 가치와 용도를 발견하기도 한다(Caru and Cova 2007; Sherry, Kazinets, and Borghini 2007). 소비자가 제품의 소비를 하나의 놀이로 인식하면서 새로운 가치 를 자발적으로 구현하는 것이다. 예를 들어 국 내의 경우 SK텔레콤이 발간한 현대생활백서 (2006)는 서비스 제공자가 예측하지 못했던 휴 대폰의 다양한 새로운 용도(단축번호의 용도변 경, 돋보기 대용, 모바일 메뉴판, 현장보존 등) 가 소비자에게 의하여 발견되고 있음을 잘 보 여주고 있다.

또한, 소비자는 새로운 소비문화를 발현하는 주체(originators of new consumption culture) 가 되고 있다. 이러한 발현적 소비현상은 한국 에서 발견되는 고유한 현상으로 볼 수도 있다. 이와 관련한 가장 대표적인 예는 2002년 월드 컵에서 나타난 길거리 응원과 2008년 전개된 촛불시위문화이다(유창조 2007). 유창조(2007) 는 2002년의 길거리 응원이 전혀 기획되지 않 은 상황에서 대규모의 군중이 모여 자발적인 역동적인 집단응원을 펼치면서 하나의 커뮤니 티의 행사가 국가적인 축제로 발전되는 과정을 분석하면서, 이러한 변화의 기저에 숨어있는 가 치로 한국이의 고유한 문화적 가치인 일체감, 구성원의 주인공의식 및 행위의 놀이적 가치를 언급한 바 있다. 또한, 유창조(2007)는 길거리 응원에서 기존 구성원의 위계적 질서가 역전되 
는 현상이 목격되었다고 언급하고 있다(예: 여 성과 남성의 지위 역전, 기성세대와 신세대의 지위 역전). 즉, Turner(1969)가 제시하는 신분 의 상승 또는 지위의 역전형상이 목격되는 것 이다. 이러한 현상은 2008년에 국가적인 관심사 였던 촛불축제에서도 발견된다. 현재 시점에서 촛불시위우의 문화적인 소비가치를 평가하기는 이르지만, 많은 언론들이 당시의 시위가 축제적 인 요소를 가미한 시위문화의 새로운 유형을 보여주고 있다고 평가하고 있고, 정부와 시민과 의 관계에서 시민의 우월적 지위를 과시한 바 있다.

이러한 현상들은 기업과 소비자의 관계에서 소비자들은 독립적인 주체성을 확보하기 시작 한 것으로 해석할 수 있다. 협업자로서의 소비 자는 기업에게 어떤 영향을 미치고자하는 목적 성을 갖고 있다면, 소비문화 발현자로서의 소비 자는 기업과의 관계를 의식하지 않고 자신들의 모임 자체를 즐기면서 자신들만의 고유한 문화 를 생성해 나가고 있다고 볼 수 있다. 과거 기 업이 기업과 고객과의 관계에서 무대의 주인공 역할을 했다고 하면, 미래에는 관람자의 역할을 하게 될 가능성이 높고, 이러한 상황에서 고객 과의 바람직한 관계를 재설정해야 하는 것이다.

\section{III. 소비자행동 연구방향에 대한 제언}

지금까지 시대적 상황에 따른 기업과 소비자 와의 관계에서 소비자의 역할변화에 대하여 탬 색해 보았다. 이상의 논의를 요약하면, 소비자
는 과거 수동적 구매자에서, 협업자로, 그리고 미래에는 새로운 소비문화의 발현자로 그 역할 을 바꾸고 있다. 따라서 소비자행동을 참구하는 연구자들도 이제 소비자에 대한 관점을 다음과 같은 새로운 각도에서 재정립할 필요가 있다.

첫째, 뉴 미디어와 혁신기술의 발달에 따른 소비자의 생활방식과 가치의 변화에 대하여 보 다 심층적인 연구가 필요한 시점이다. 예를 들 어, 10 대의 경우 뉴 미디어를 사용하는 방식, 제품을 수용하는 과정 등이 기성세대와 다름이 확인되고 있다. 소비자들의 생활방식과 소비가 치가 변화하면서 제품을 평가하는 방식과 기준 이 바뀔 가능성이 높다. 또한 수동적인 상황에 서의 평가와 주도적인 관점에서의 평가방식도 다를 것이다. 능동적인 소비자의 관점에서 소비 자의 의사결정과정과 각 단계별 방식은 재조명 될 필요가 있다. 예를 들어, 불만족한 소비자가 취하는 불평행동에 관한 연구들은 개인적인 차 원에서의 대응에서 집단적인 차원에서의 대응 으로 확대되어 분석될 필요가 있다. 더 나아가 불평행동이라는 개념도 수동적인 소비자의 관 점이 반영된 것이기 때문에 협업자나 주도자의 관점에서 재정의될 필요도 있다.

둘째, 이제 소비자를 정보 제공자로서 분석할 필요가 있다. 과거의 연구가 주로 소비자들 정 보 수용자로 분석해 왔다면, 지금의 소비자는 정보 제공자, 정보 변형자의 관점에서 이들이 제공하는 정보의 영향과 정보가 확산되는 과정 을 분석할 필요가 있다. 최근 인터넷을 기반으 로 한 정보의 재생산과 확산이 부분적으로 진 행되고 있지만, 아직도 정보 수용자의 관점에서 연구가 진행되고 있다. 이런 관점에서 문화 생 산 시스템(과거의 모델은 소비자를 새로운 문 
화의 개척자가 아니라 수용자로 보고 있음)도 소비자를 중심으로 재분석될 필요가 있다.

셋째, $\mathrm{IMC}$ 의 개념도 소비자의 주도성을 반영 할 필요가 있다. 과거 학계에서 제시되어 왔던 $\mathrm{IMC}$ 의 개념은 소비자의 접점을 중심으로 기업 관점 전달하는 메시지의 통합적 관리였다고 볼 수 있다. 소비자들이 기업과 관련된 메시지를 자발적으로 생성되고 있는 상황에서 이제 기업 은 소비자들이 제공하는 메시지를 어떻게 해석 하고 통합적으로 대응해야 할 것인가를 고민해 야 할 시점에 와 있다.

넷째, 소비자의 지위가 역전됨에 따라 소비자 의 지위 역전에서 올 수 있는 규범적 문제를 연구할 필요가 있다. 지금까지 기업의 윤리와 사회적 책임이 강조되어 왔다면, 앞으로는 소비 자의 윤리와 소비자의 사회적 책임이 강조될 필요가 있다. 이미 네티즌의 폭력성 정보 확산 등이 사회문제로 부각되고 있다. 이러한 소비자 의 정보재생산과 관련하여 정보의 확산과정과 단계별 참여자의 심리 및 경험적 가치에 대한 연구가 시급한 시점이라고 하겠다.

마지막으로, 소비자 네트워크에서 구성원들 간 위계적인 위치에 대한 연구가 요구된다. 선 행 연구결과들은 브랜드 커뮤니티의 위계적 질 서(예: 선도자(soft core)와 추종자(hard core) 로 구분됨)를 언급하고 있다(Schouten and McAlexander 1995). 그러나 유창조(2007)는 붉은 악마 커뮤니티에서 수평적 관계가 집단문 화가 확산될 수 있었던 주요 요인으로 해석한 바 있다. 따라서 소비자 커뮤니티 내에서의 구 성원들 간 관계 유형에 관한 연구는 소비자의 발현적 소비현상을 보다 심층적으로 이해할 수 있는 단서가 될 수 있을 것이다.

\section{참고문헌}

유창조(2007), "월드컵 축구경기에서 표출되는 팬의 소비가치에 대한 비교연구: 국가별 팬 집단의 소비행태 및 소비문화의 비교," 마 케 팅연구, 22(4), 115-140.

유창조(2008), "뉴 미디어 시대에서의 소비자 역 할 변화에 대한 탐색," 2008년도 조사학회

춘계학술대회 발표논문집, 2008년 6월 13일. 유창조, 김미나(2007), “경험적 가치기반의 매장

에 관한 Ethnography: 홍대 앞 프리마켓 (free market)을 중심으로," 유통연구, 12 권 3호, 1-21.

유창조, 백지은(2006), "미술관 체험에 관한 ethnography: 참여적 소비를 중심으로,” 2006 년도 마케팅학회 춘계학술대회 발표논문집, 2006년 3월 4일.

임종원, 양석준(2006), “디지털 환경에서 고객 참여를 통한 고객 주도형 관계 구조 형성에 관한 탐색적 연구," 한국마케 팅저널, 8권 2 호, 19-48.

주우진, 김재범(2002), 인터넷 마케팅, 법문사: 서울

현대생활 백서(2006), 고객이 만든 현대생활백 서, SK텔레콤.

Betman(1979), An Information Processing Theory of Consumer Choice, MA: Addison-Wesley.

Caru, Antonella and Benard Cova(2007), Consuming Experience, Routledge Inc.

Gennep, Arnold Van(1909), The Rites of Passage, London: Routledge and Kegan Paul. Hirshman, Elizabeth E. and Morris B. Holbrook 
(1982), "Hedonic Consumption, Emerging Concepts, Methods, Propositions," Journal of Marketing, 46(Summer), 92-101.

Holbrook, Morris B. and Elizabeth E. Hirshman (1983), "The Experiential Aspects of Consumption: Consumer Fantasies, Feelings, and Fun," Journal of Consumer Research, 9(September), 132-140.

Jenkins, Henry(2006). Convergence Culture: Where Old and New Media Collide, New York, University Press.

Kelley, Kevin(1998), New Rules for the New Economy, Penguin Books.

Lancaster, Kurt(1997), "When Spectators Became Performers: Contemporary PerformanceEntertainment Meet the Needs of an Unsettled Audience," Journal of Popular Culture, 30, 75-88.

McAlexander, James H., John W. Schouten, \& Harold F. Koenig(2002), "Building Brand Community," Journal of Marketing, 66 (January), 38-54.

Pine, Joseph, and James Gilmore(1999), The Experience Economy, Boston: Harvard Business School Press.
Schmitt, Bernd(2003), Customer Experience Ma-nagement, Hoboken, NJ: John Wiley \& Sons.

Schouten, J. W. and J. H. McAlexander(1995), "Subculture of Consumption: An Ethnography of New Bikers," Journal of Consumer Research, 22, 42-61.

Seybold, Patricia(2002), Customer Revolution, New York, Vrown Business.

Sharma, Arun and Jagdish N. Sheth(2004), "Web-based Marketing: The Coming Revolution in Marketing Thought and Strategy." Journal of Business Research, 57, 696-702.

Sherry, John F., Rovert V. Kazinets, and Stefania Borghini(2007), "Agents in paradise: experiential $\mathrm{Co}^{-}$creation through emplacement, ritualization, and community," Chapter 2 in Consuming Experience, Edited by Antonella Caru and Benard Cova, 1733.

Tuner, Victor(1969), The Ritual Process: Structure and Anti-structure, Aldine Publishing Company, Chicago, Illinois. 